\title{
NMDA-Dependent Modulation of CA1 Local Circuit Inhibition
}

\author{
Heinz C. R. Grunze, ${ }^{1}$ Donald G. Rainnie, ${ }^{1}$ Michael E. Hasselmo, ${ }^{2}$ Eddie Barkai, ${ }^{2}$ Elizabeth F. Hearn, ${ }^{1}$ \\ Robert W. McCarley, ${ }^{1}$ and Robert W. Greene ${ }^{1}$ \\ 1Department of Psychiatry, Harvard University and Brockton VAMC, Brockton, Massachusetts 02401, and 2Department \\ of Psychology, Hanvard University, Cambridge, Massachusetts 02138
}

\begin{abstract}
Whole-cell and extracellular recording techniques were used to examine local circuit inhibition in the CA1 region of the rat hippocampus in vitro. Activation, primarily of the recurrent inhibitory circuit by alvear stimulation, elicited an IPSP in pyramidal neurons that was dependent, in part, on NMDA receptor activation. Application of a tetanizing stimulus to the alveus evoked long-term potentiation (LTP) of the intracellularly recorded recurrent IPSPS. This LTP also was NMDA-dependent and was more sensitive to blockade by the NMDA antagonists 2-amino-5-phosphonovalerate (APV) and $N$-acetyl-aspartylglutamate, than the excitatory LTP produced by Schaffer collateral stimulation. With regard to APV, the sensitivity of inhibitory LTP was an order of magnitude greater.
\end{abstract}

A biophysical simulation of hippocampal CA1 circuitry was used in a model of learned pattern recognition that included LTP in both excitatory and inhibitory recurrent circuits. In this model, selective blockade of inhibitory LTP produced aberrant spread of lateral excitation, resulting in confusion of normally distinguishable patterns of neuronal activity. Consideration is given to the possibility that selective disruption of NMDAdependent modulation of local circuit inhibition may serve as a model for some aspects of dysfunction associated with NMDAantagonist exposure and schizophrenia.

Key words: recurrent inhibition; long-term potentiation; AP5; phencyclidine; $\mathrm{N}$-acetylaspartyl-glutamate; signal processing; schizophrenia
Throughout the CNS, local circuit inhibition plays an integral role in both neuronal network processing and the regulation of the excitability of projection neurons. Local circuit inhibition includes two main types: feedforward inhibitory circuits that are characterized by the extrinsic origination of interneuronal excitation, and recurrent or feedback circuits in which the interneuronal excitation originates from recurrent collaterals of local excitatory projection neurons. Because the recurrent circuit is activated whenever a projection neuron is activated, it is an integral component of the projection cells' output. Recurrent inhibitory circuits may be particularly important to signal processing in cortical networks with pronounced recurrent excitatory interactions, such as the hippocampus (Miles and Wong, 1986; Miles and Wong, 1987a,b; Radpour and Thomson, 1991; Thomson and Radpour, 1991). Recurrent inhibition may limit not only the lateral spread of recurrent excitation, but also the duration of its effect, because the recurrent inhibition overlaps temporally with recurrent excitation. In addition, the divergent spread of local circuit inhibition (Buzsaki et al., 1992; Buhl et al., 1994; Whittington et al., 1995) may facilitate discharge synchronization of projection neurons by producing a synchronous relative refractory period.

Any mechanism that alters the strength of local circuit inhibition in a network would be expected to alter the signal-processing function of this network. Extrinsic modulation of cortical networks by neurotransmitters from such diverse systems as the noradrenergic, serotonergic, histaminergic, and cholinergic nuclei may exert an influence on network function that is not directly

Received May 26, 1995; revised Dec. 15, 1995; accepted Dec. 18, 1995.

This work was supported by the Department of Veterans Affairs. H.C.R.G. is supported by a grant from the Deutsche Forschungsgemeinschaft. We are thankful for anatomical advice from M. Frotscher, Freiburg, Germany.

Correspondence should be addressed to R. W. Greene, VAMC 151 C, 940 Belmont Street, Brockton, MA 02401

Copyright (C) 1996 Society for Neuroscience $0270-6474 / 96 / 162034-10 \$ 05.00 / 0$ dependent on the output of the network. A less frequently addressed site of intrinsic modulation is in the local inhibitory networks of the CA1 region, more specifically, the glutamatergic synapse onto inhibitory interneurons, which activates both NMDA and non-NMDA receptors (Sah et al., 1990). Activation of NMDA receptors may act as an intrinsic modulatory influence in two ways: first, by acutely enhancing local circuit inhibition, and second, by activating long-term potentiation (LTP) of this circuit.

NMDA-dependent LTP of glutamatergic transmission onto projection neurons is the best-characterized form of activitydependent synaptic plasticity in the mammalian CNS (Bliss and Lømo, 1973; Anderson et al., 1977; Bliss and Collingridge, 1993). However, findings from in vivo studies also have provided evidence consistent with modulation of inhibitory pathways by LTP in the hippocampus (Buzsaki and Eidelberg, 1982) and other CNS local circuits (Korn et al., 1992). In addition, in vitro investigations in the hippocampus have reported both NMDA-dependent LTP and NMDA-dependent long-term depression (LTD) of feedforward inhibitory pathways (Stelzer et al., 1994). Because of the importance of recurrent inhibition in network functioning, we have examined the effects of, and sensitivity to, NMDA antagonists on the IPSPs and LTP of these IPSPs in the CA1 region of hippocampal slices that were transected to minimize feedforward inhibition. We report here that under these conditions, the IPSP is reduced acutely by 2-amino-5-phosphonovalerate (APV), and a LTP of this IPSP can be evoked that is highly sensitive to APV, $N$-acetyl-aspartylglutamate (NAAG), or phencyclidine (PCP).

\section{MATERIALS AND METHODS}

Slices were prepared from Long-Evans rats of both genders, age $25-40 \mathrm{~d}$. Rats were decapitated under halothane anesthesia, and the brains were removed rapidly and $400-\mu$ m-thick transverse slices cut from the hippocampus using a vibratome. Slices then were placed in artificial CSF (ACSF) that contained (in mM): $\mathrm{NaCl} \mathrm{124;} \mathrm{KCl} \mathrm{3.75;} \mathrm{KH}_{2} \mathrm{PO}_{4} 1.25$; 
A

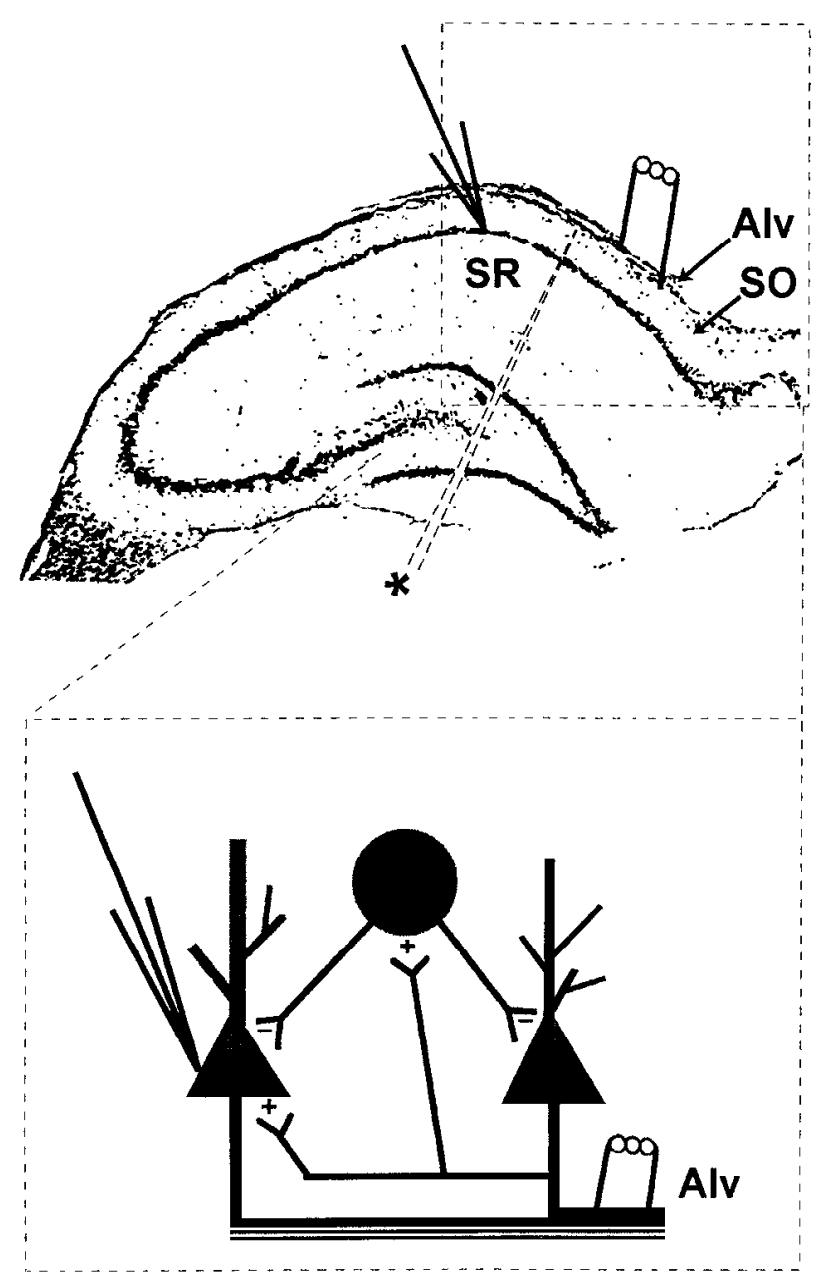

B

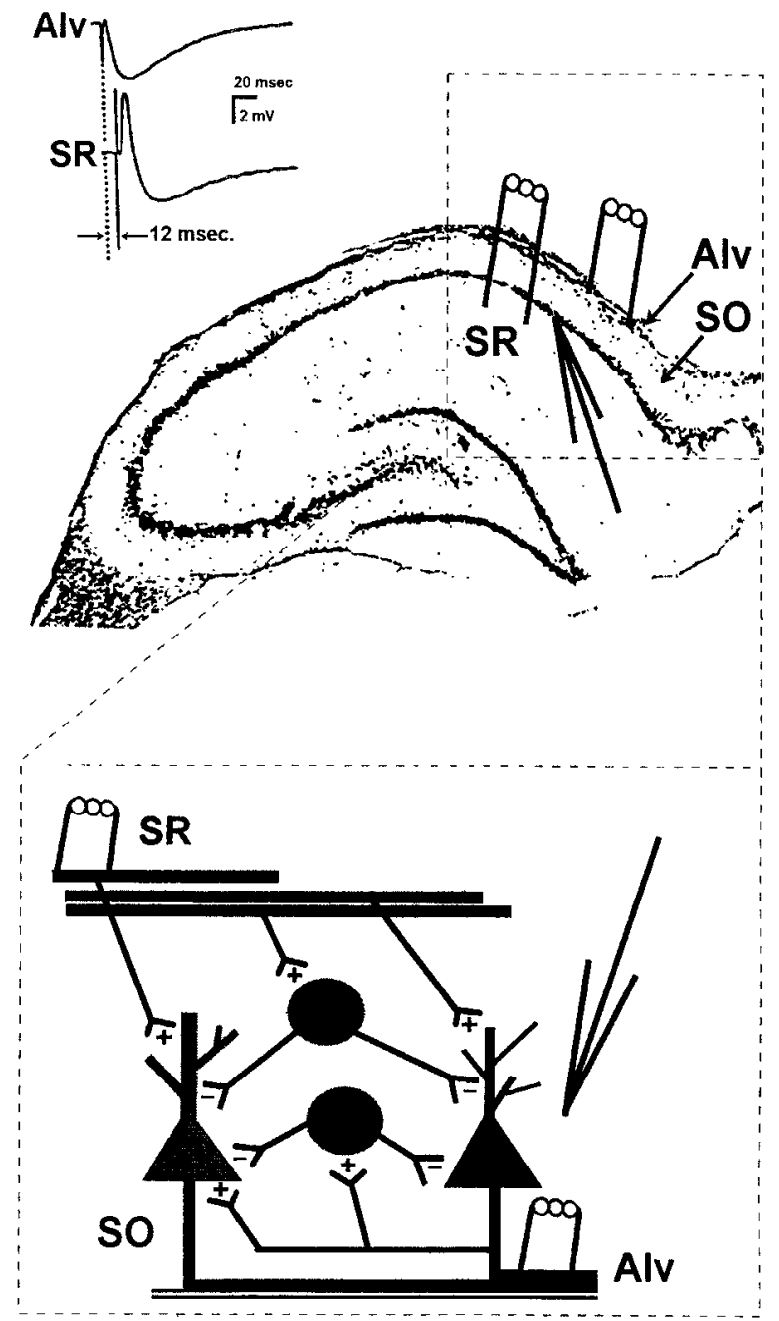

Figure 1. Placement of recording and stimulation electrodes for whole-cell patch-clamp and extracellular recordings. $A$, The top portion is a scanned image of a transverse section of the rat hippocampus showing the placement of recording and stimulating electrodes for whole-cell patch-clamp recording. The location of the knife cut in the acutely transected slices is indicated by the dashed lines marked by the asterisk. The bottom portion shows a schematic of the assumed basic neuronal circuit with the stimulation electrode in the alveus and the recording electrode in a CA1 pyramidal cell. $B$, The top portion shows the placement of recording and stimulating electrodes for extracellular recordings. The bottom portion shows a schematic of the assumed basic neuronal circuit. The inset at the top shows two traces of synaptic potentials recorded intracellularly from a CA1 neuron after electrical stimulation (fast downward deflection) of the $A l v$ and $S R$. The SR trace has been shifted to the right to reflect the $12 \mathrm{msec}$ delay used in the paired-pulse paradigm. Note the peak of the Alv-evoked IPSP coincides with the peak of the SR-evoked EPSP. When transected slices were used (see Materials and Methods for description), the alveus was the site of stimulation for both intra- and extracellular recordings.

$\mathrm{MgCl}_{2} 1.3 ; \mathrm{CaCl}_{2} 3.5 ; \mathrm{NaHCO}_{3} 26$; and glucose 10 . This was bubbled with $95 \% \mathrm{O}_{2} / 5 \% \mathrm{CO}_{2}$ and maintained at $30 \pm 2{ }^{\circ} \mathrm{C}$ throughout the recordings. Whole-cell recordings were obtained with borosilicate glass electrodes (resistance 4-6 $\mathrm{M} \Omega$ ) filled with (in mM): K-citrate 120; $\mathrm{CaCl}_{2} 1 ; \mathrm{MgCl}_{2} 3$; MgATP 2; NaGTP 2; EGTA 3; and HEPES 40 (modified from Blanton et al., 1989). Free calcium was calculated to be $\sim 40 \mathrm{~nm}$, using a program, CaBuf (written by G. Droogmans, Catholic University of Leuven, Leuven, Belgium). Recordings in current clamp mode, using a bridge circuit, were made from hippocampal CA1 neurons with an Axoclamp 2A amplifier (Axon Instruments, Burlingame, CA). Extracellular recordings were made with the same electrodes as those used for intracellular whole-cell patch-clamp recordings, except that they were filled with ACSF.

Stimulation procedure. IPSPs in CA1 pyramidal neurons were evoked by stimulation of the alvcus (Alv) or the stratum oriens (SO) (Spencer and Kandel, 1961; Andersen et al., 1963) and examined with whole-cel patch recordings (see circuit sketch in Fig. $1 A$ ). The SO and alveus contain afferent axons that terminate not only in the SO, but also in the stratum pyramidale (SP) and the stratum radiatum (SR), and include commissural fibers (Frotscher and Zimmer, 1983; Léránth and Frotscher, 1983) and ipsilateral projections from CA3 (Amaral and Witter, 1989; Li et al., 1994). Stimulation of the SO, therefore, would be expected to evoke both feedforward and recurrent inhibition. The present study attempted to limit activation of feedforward inhibition and excitation in the $\mathrm{SO}$ by the use of transected slices with a knife cut that extended from the SO-alvear border through the stratum lacunosum-moleculare, so that only the alveus was spared. In this paradigm, the Alv stimulus electrode and the recording electrode were placed on opposite sides of the lesion (Dingledine and Langmoen, 1980; Alger and Nicoll, 1982). For extracellular recordings, the SR-stimulus electrode was placed on the same side of the cut as the recording electrode. In an additional set of experiments, animals were anesthetized (acepromide-ketaminerompum mixture $0.2 \mathrm{ml} / 100 \mathrm{mg}$ ) and the commissural fibers lcsioncd, under stereotaxic guidance, with a knife cut that completely severed the contralateral connections in the fimbria of the dorsal hippocampus. Animals then were allowed 4 d postoperative recovery before harvesting the hippocampal slices. The location of the lesion was verified visually when the slices were obtained. These slices then were transected acutely as described above to isolate the recurrent inhibitory circuit.

A tetanus of four trains of 10 stimuli at $100 \mathrm{~Hz}$ was applied to induce LTP (a tetanus of 20 stimuli at $400 \mathrm{~Hz}$ originally was used with nontransected slices shown in Fig. 2 with similar results). During the tetanus, the pyramidal neuron was hyperpolarized to $-85 \mathrm{mV}$ with $\mathrm{DC}$ current 


\section{A}

Figure 2. APV causes a dosedependent reduction of the IPSP. $A$, Voltage traces from a whole-cell patchclamp recording of a $\mathrm{CAl}$ pyramidal neuron in a transected slice APV (25 $\mu \mathrm{M})$ caused a reversible reduction in the peak amplitude of the IPSP, but not of the EPSP. $B$, A recording from another CA1 pyramidal neuron shows that 0.4 $\mu \mathrm{M}$ APV reduced the IPSP amplitude by $14 \%$, approximately one-third of the maximal IPSP reduction of $34 \%$, evoked by $25 \mu \mathrm{M}$ APV. $C$, A histogram illustratcs the cffect of $0.4,3$, and $25 \mu \mathrm{M}$ APV on the amplitude of the IPSP in whole-cell patch-clamp recordings, as shown in $A$ and $B$.
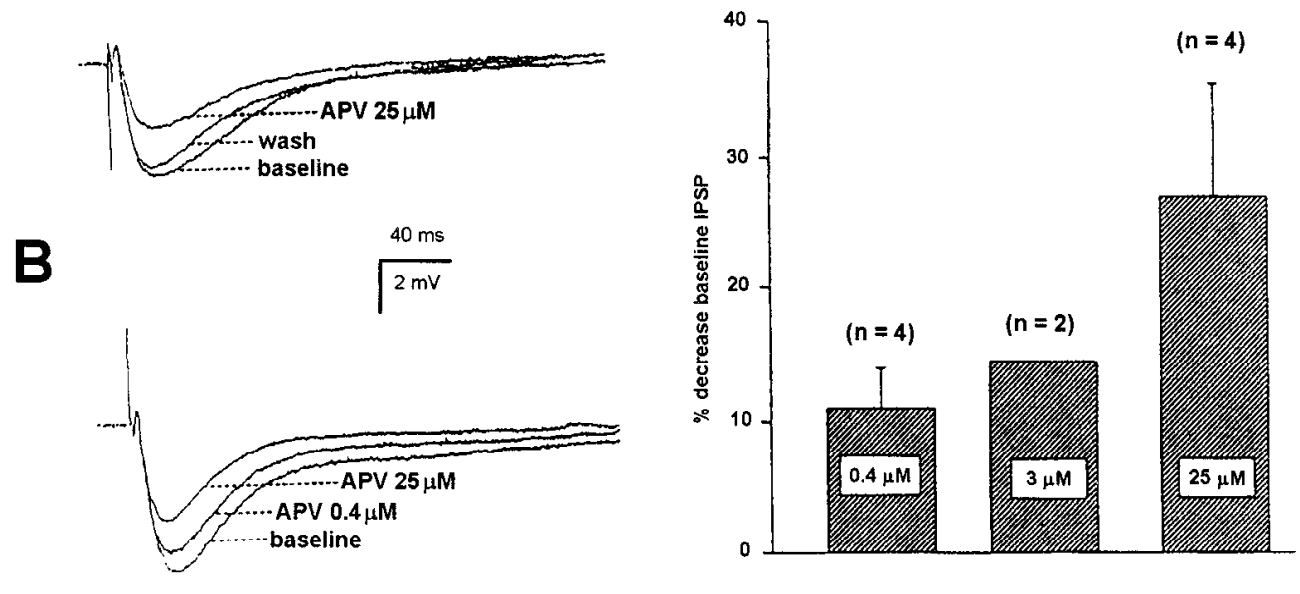

[APV] $\mu \mathrm{M}$ injection to prevent the induction of recurrent excilatory LTP onto the recorded neuron itself (Malinow and Miller, 1986). Pcak baseline values of evoked IPSPs before tetanus were compared with peak values obtained continuously for at least 21 min after the tetanus; membrane input resistance was monitored every 3 min during this period.

For extracellular recordings, a paired-pulse stimulation paradigm, adapted from Bourne et al. (1983), was used to examine inhibitory LTP. One of two bipolar stimulating electrodes was placed in the SR to evoke orthodromic population spikes (PS) of CA1 pyramidal neurons ( $\mathrm{PS}_{\mathrm{SR}}$ ). PS amplitude was determined as the mean of 10 responses recorded at 20 sec intervals. The second bipolar electrode was used to activate recurrent inhibitory circuits by stimulation of the alveus 12 msec before the stimulation of the SR. The amplitude of the paired $\mathrm{PS}_{\mathrm{SR}}$ was reduced compared with the unpaired $\mathrm{PS}_{\mathrm{SR}}$. This paired-pulse PS was called $\mathrm{PS}_{\mathrm{Alv}, \mathrm{SR}}$. Fig $1 B$ shows the placement of stimulation and recording electrodes, and Figure 4, $A$ and $C$, shows the extracellular voltage trace that follows the unpaired and paired stimuli. The amplitude of the PS $\mathrm{SR}_{\mathrm{SR}}$ was compared with its amplitude during the paired-pulse paradigm by the ratio $\mathrm{PS}_{\mathrm{Alv}, \mathrm{SR}} / \mathrm{PS}_{\mathrm{SR}}$. A tetanus (four trains of 10 stimuli at $100 \mathrm{~Hz}$ ) then was applied to the Alv pathway and the ratio of $\mathrm{PS}_{\mathrm{Alv} S \mathrm{SR}} / \mathrm{PS}_{\mathrm{SR}}$ determined before tetanus was compared with that at three time intervals $(2,10$, and $20 \mathrm{~min}$ ) after tetanus. All data of evoked field and intracellular potentials are average values of five to eight recordings taken with a time interval of $20 \mathrm{sec}$.

Dose-response relationships for excitatory and inhibitory LTP were generated with at least four sample points per concentration. The doseresponse relationship was fit with a sigmoid curve using Sigmaplot and least squares analysis. The equation for the curve was as follows:

$$
y=\frac{100}{1+\operatorname{cxp}[A P V]-x},
$$

where $k=$ the slope factor; $[A P V=$ the concentration of APV in micromolars, and $x=\mathrm{IC}_{50}$, when $[A P V]=x$ then $\mathrm{y}=50$.

Results are given as means $\pm \mathrm{SE}$, except for the parameter derived from the curve fit, $\mathrm{IC}_{50}$, which is expressed with \pm the asymptotic $\mathrm{SE}$.

Simulation of CAI network activity. The computer simulation presented here was adapted from a simulation of the piriform cortex (Barkai et al., 1994; Barkai and Hasselmo, 1994; Hasselmo and Barkai, 1995), which was developed using the Genesis simulation package (Wilson and Bower, 1992; Bower and Beeman, 1995). Starting parameters for most currents wcre derived from a previous simulation of hippocampal region CA3 (Traub et al., 1992). These simulations represent the membrane potential dynamics of cortical neurons based on an equivalent circuit model of passive membrane properties combined with representations of voltagedependent conductances using the Hodgkin-Huxley framework.

The simulation contained 240 biophysical compartmental simulations of pyramidal cells, using parameters presented in previously published work (Traub et al., 1992; Barkai and Hasselmo, 1994; Hasselmo and
Barkai, 1995). Each simulated pyramidal cell consisted of three compartments. One compartment represented the somal, and two compartments represented proximal and distal dendritic regions. Equivalent circuit representations were used to model the passive nembrane propertics dependent on membrane resistance and capacitance along with axial resistance between compartments (Bower and Beeman, 1995). Both dendritic compartments contained excitatory synaptic sodium currents, whereas the proximal dendritic compartment contained synaptically activated inhibitory potassium currents, and the soma contained synaptically activated inhibitory chloride currents.

Because of the small size of the network, a higher percentage of excitatory synaptic connectivity was used (see Discussion in Wilson and Bower, 1992). Each pyramidal cell contacted $\sim 70 \%$ of other pyramidal cells with excitatory currents that evoked synaptic potentials having a dual exponential time course witlı a rise lime constant of $1 \mathrm{msec}$ and a decay time constant of $3 \mathrm{msec}$ (additional description provided in Barkai et al., 1994; Hasselmo and Barkai, 1995). The network also contained 58 each of two groups of inhibitory interneurons. These interneurons received excitatory synaptic input from pyramidal cells and from afferent input, and activated inhibitory synaptic potentials having a dual exponential time course with time constants of $1 \mathrm{msec}$ rise and $7 \mathrm{msec}$ decay for chloride currents, and time constants of $10 \mathrm{msec}$ rise and $100 \mathrm{msec}$ decay for potassium currents. These time constants replicated the different time course of $\mathrm{GABA}_{\mathrm{A}^{-}}$and $\mathrm{GABA}_{\mathrm{B}}$-mediated currents. The soma compartment contained a range of voltage-dependent currents, including the fast-activating sodium current $\left(\mathrm{I}_{\mathrm{Na}}\right)$ and delayed-rectificr potassium current underlying generation of action potentials (see Fig. 5). In addition, the soma compartment contained representations of the voltagedependent potassium currents $\mathrm{I}_{\mathrm{A}}$ and $\mathrm{I}_{\mathrm{M}}$. Parameters for these currents are provided in previously published work (Traub et al., 1992; Barkai and Hasselmo, 1994; Hasselmo and Barkai, 1995). These pyramidal cells undergo adaptation in response to sustained current injection caused by activation of a voltage-dependent calcium current $\left(\mathrm{I}_{\mathrm{C} i}\right)$, which increases intracellular calcium levels and activates a calcium-dependent potassium current $\left(I_{K(A I I P)}\right)$. The parameters for these currents also are provided in previous articles (Traub et al., 1992; Barkai and Hasselmo, 1994; Hasselmo and Barkai, 1995).

Simulations tested the capacity of the network to store patterns of afferent input and recall these full patterns of activity given degraded versions of these input patterns. The simulations used scparatc "lcarning" and "recall" phases, as described in previous work (Barkai and Hasselmo, 1994; Hasselmo and Barkai, 1995).

During learning, the network received consecutive presentation of two full patterns of afferent input (the triangular patterns seen in Fig. 6, left). Afferent input consisted of activation of synapses in the distal dendritic compartment of 40 of 240 pyramidal cells. Each of these 40 neurons received a pattern of input characterized by theta and gamma oscillatory activity as reported for olfactory cortex electroencephalography during learning (Wilson and Bower, 1992). This consisted of groups of four synaptic potentials at $25 \mathrm{msec}$ intervals, with $200 \mathrm{msec}$ between the start 
of each burst. This results in the pattern of firing seen in Figure 6, right. The patterns overlapped considerably, such that eight neurons received input during both pattern $I$ and pattern 2 . The strength of excitatory synapses between pyramidal cells was changed during learning according to a Hebbian learning rule. When a spike arrived at a particular synapse, the maximal conductance of the synaptic current was increased in proportion to how much the postsynaptic membrane potential exceeded a modification threshold. During recall, the network was presented with degraded versions of the stored afferent input patterns. Recall was tested in two conditions: (1) after strengthening of excitatory synapses between pyramidal cells and inhibitory interneurons, and (2) with no increase in strength of input to inhibitory interneurons. The degraded input for each pattern activated only 24 of the 40 neurons activated during learning. (As seen in Fig. 6, neurons in the overlap did not receive input.) The spiking activity of the network was observed during a $500 \mathrm{msec}$ period, during which the network received afferent input consisting of three groups of four synaptic potentials. The performance of the network during recall is described in the Results section.

\section{RESULTS}

In control slices, low-frequency electrical stimulation $(0.05 \mathrm{~Hz}$, 0.5-1 $\mu \mathrm{A} ; 400 \mu \mathrm{sec}$ duration) of the SO or Alv evoked a multiphasic postsynaptic potential consisting of an EPSP and subsequent fast and slow IPSPs when recorded with intracellular patch electrodes. In agreement with previous studies (Curtis et al., 1970) (for review, see Stelzer, 1992), the early Alv-cvoked IPSP was antagonized (mean reduction of IPSP, $47+6 \%$ ) by pressureejected bicuculline $(10 \mathrm{~mm} ; 100 \mathrm{msec} ; 3 \mathrm{psi} ; n=9)$, indicative of a potential mediated by activation of $\mathrm{GABA}_{\wedge}$ receptors. In contrast, the late phase of the IPSP was blocked by the $\mathrm{GABA}_{\mathrm{B}}$ receptor antagonist saclofen $(250 \mu \mathrm{M})$. The EPSP has been reported previously to be mediated by activation of AMPA-kainate receptors and also NMDA receptors (Hestrin et al., 1990; Thomson and Radpour, 1991).

The IPSP evoked in control (nontransected slices; $n=31$ ) had a peak amplitude of $4.6 \pm 0.3 \mathrm{mV}$, which was not significantly different $(p<0.05$; Wilcoxon signed-ranks) from the peak IPSP amplitude of transected slices $(n=30)$ of $6.7 \pm 0.5 \mathrm{mV}$. In slices in which the SO, SP, and SR had been transected, the peak amplitude of the IPSP evoked after stimulation of the alveus from either the fimbrial $(n=14)$ or the subicular side $(n-16)$ of the transection showed no significant difference $(6.5 \pm 0.7 \mathrm{mV}$ vs 6.7 $\pm 0.8 \mathrm{mV})$.

Activation of afferent excitatory input to CA1 interneurons evokes an EPSP with an NMDA component (Sah et al., 1990) that may be present during baseline (non-high-frequency activation) conditions (Lacaille, 1991). We observed that superfusion of APV, although having no apparent effect on the SR-evoked EPSP, caused a dose-dependent reduction of the evoked IPSP (Fig. 2). Hence, in 10 of 13 neurons tested, $25 \mu \mathrm{M}$ APV reduced the IPSP by $27 \pm 4 \%(n=4), 3 \mu \mathrm{M}$ APV by $14.5(n=2)$, and 0.4 $\mu \mathrm{M}$ APV by $11 \pm 1 \%(n=4)$ (Fig. $2 B)$. This result is illustrated graphically in Fig $2 C$. In the remaining three neurons, the IPSP was insensitive to APV, but was blocked by $5 \mu \mathrm{M} 6$, 7-dinitroquinoxaline-2,3-dione (data not shown). The reduction in IPSP amplitude was reversible on washout of APV (see Fig 2A), suggesting that NMDA receptor activation is a necessary component of the low-frequency glutamatergic drive onto inhibitory interneurons.

A tetanus applied to the Alv in control slices resulted in an initial post-tetanic potentiation (PTP) of the IPSP (Fig. 3A1,2), which declined to a stable longer-term potentiation (Fig. $3 A, 3$ ) $\sim 15$ minutes after tetanus. The mean increase in the IPSP, measured $>20$ min after the telanus, was $28 \pm 6 \%$. In addition, tetanic stimulation of the Alv $(n=2)$, in the presence of saclofen, had no effect on the expression of either PTP, short-term potentiation (STP) (Malenka and Nicoll, 1993) or LTP of the IPSP, suggesting that the observed inhibitory LTP is attributable to potentiation of $\mathrm{GABA}_{\mathrm{A}}$-mediated transmission. Further, the reversal potential of the IPSP (between -70 and $-75 \mathrm{mV}$ ) did not change after tetanus induced LTP $(n=4)$, suggesting that an alteration of the chloride driving force is not responsible for the enhanced IPSP. Finally, an apparent increase in the IPSP attributable to homosynaptic LTP of the overlapping recurrent EPSP cannot be ruled out. However, this is an unlikely mechanism, because, (1) the parameters of the tetanus employed typically evoke homosynaptic LTD (Malenka and Nicoll, 1993), and (2) when the alvear-evoked synaptic potential is examined at the IPSP reversal potential $(-70$ $\mathrm{mV}$ ) before and $40 \mathrm{~min}$ after the tetanus, no decrease or a slight increase in the EPSP amplitude is observed $(n=2$ in transected slices) (Fig. 3C3).

In transected slices, the effects of tetanic stimulation of the alveus were examined in every neuron that showed a stable input resistance ( $<5 \%$ change from bascline for the duration of the recording, measured every $10 \mathrm{~min})$. Tetanic stimulation of the alveus $(n=15)$ resulted in an increase of the IPSP amplitude of $50 \pm 10 \%, 21 \mathrm{~min}$ post-tetanus. The majority of neurons (12/15) showed an increase of amplitude with a range from 15 to $238 \%$; the IPSP of the remaining three neurons changed $<5 \%$. Stable recordings of durations $\geq 40 \mathrm{~min}$ posttetanus $(n=6)$ showed an increase of IPSP amplitude of $52 \pm$ $16 \%$ ( $p \leq 0.005$; Mann-Whitney U test) (Fig. 3A,Cl). Figure $3 D 1$ shows the time course of LTP in these six neurons compared with the mean IPSP amplitude of four other neurons that were not tetanized.

To gain an improved isolation of recurrent circuits resulting from Alv stimulation, commisural fibers were transected in vivo $4 \mathrm{~d}$ before an additional acute transection in vitro. Inder these conditions, the EPSP portion of the antidromically activated EPSP-IPSP sequence is more prominent (Fig. 3B), possibly as a result of decreased inhibitory feedforward activation (Frotscher and Zimmer, 1983; Léránth and Frotscher, 1983; Miles and Wong, 1987b). After tetanic stimulation, the IPSP amplitude showed both PTP-STP and LTP (an increase of $50 \pm 13 \%$, measured at $40 \mathrm{~min}, n=3$; Figs. $3 B$ and $C 2$ ). Figure $3 D 2$ shows the effect of tetanic stimulation of the SR on the SR-evoked EPSP, using identical stimulation parameters as in the transected slice. The excitatory pathway shows both a PTP-STP and an LTP, which has a time course similar to that of the inhibitory LTP.

Many studies have demonstrated an NMDA-mediated component of the Schaffer collateral excitatory LTP (Collingridge et al., 1983; Harris et al., 1984; Herron et al., 1986). Consequently, we examined the dependence of the LTP of Alv-evoked inhibition on NMDA receptor activation. First, the NMDA-receptor antagonist APV $(25 \mu \mathrm{M})$ was perfused during tetanic stimulation, then the APV was removed and the effects on inhibitory LTP determined in control ACSF. Under these conditions, no inhibitory LTP was observed $(n=6)$; however, PTP was observed in three neurons $(26 \pm 13 \%)$, which decayed back to baseline in $<10 \mathrm{~min}$. The specific site and mechanism of the APV-sensitive inhibitory LTP was not identified, although a likely site, consistent with the NMDA-dependence, is the excitatory synapse of recurrent collaterals onto GABAergic interneurons (see circuit schematic in Fig. 1).

We further evaluated alterations in synaptic transmission in the CA1 network with stimulus-evoked extracellular field potentials, a technique that allows longer, more stable recordings than wholc- 
A

1.

2.

3.

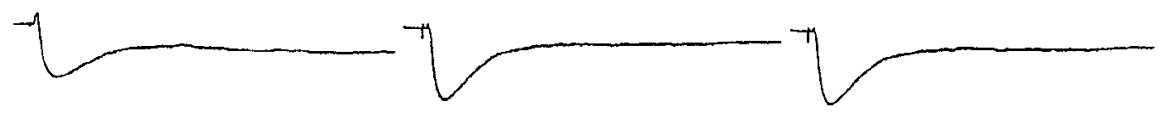

B 1 .

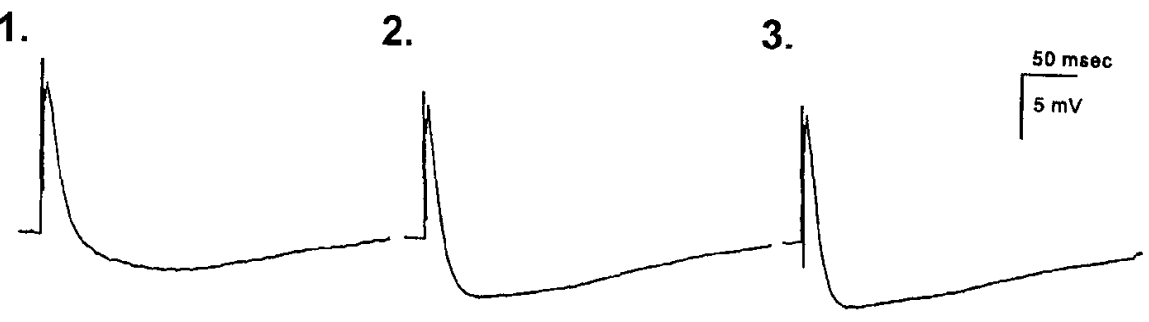

Figure 3. Tetanic stimulation of the alveus results in LTP of the IPSP. $A$, The voltage records are averages of five traces from whole-cell patch-clamp recordings of a CA1 pyramidal neuron in an acutely transected slice. The input resistance remained constant at $100 \mathrm{M} \Omega$ throughout the recording. Postsynaptic potentials were recorded ( 1 ) beforc, (2) $20 \mathrm{~min}$ after, and (3) $40 \mathrm{~min}$ after tetanic stimulation of the alveus. $B$, The records are similar to those of $A$ except that in these slices, the commissural pathway was lesioned previously in vivo in addition to the acute transection. $C$, Records from $A l$ and $A 3$ and from $B I$ and $B 3$ are superimposed for comparison in $\mathrm{Cl}$ and $C 2$, respectively. In $C 3$, superimposed voltage traces are shown that are similar to those of $C l$, except that the membrane potential was held at the IPSP reversal potential to isolate the EPSP. The trace taken 40 min after the tetanus (indicated by the arrow) did not show LTD. D1, A graph of the average peak amplitude \pm SE (error bars often fall within the symbol) of the IPSP in response to stimulation of the alveus versus time in CA1 pyramidal cells from slices transected in vitro (solid square indicates tetanized slices, $n=4$; solid circle indicates nontetanized slices, $n=$ 4). D2, A graph of the peak amplitude of the EPSP with respect to time in a typical CA1 pyramidal cell in response to tetanic stimulation of the SR using the same stimulation parameters.

1.

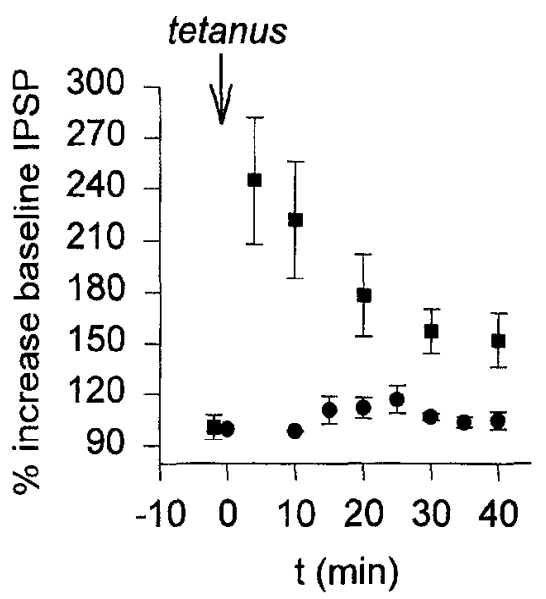

2.

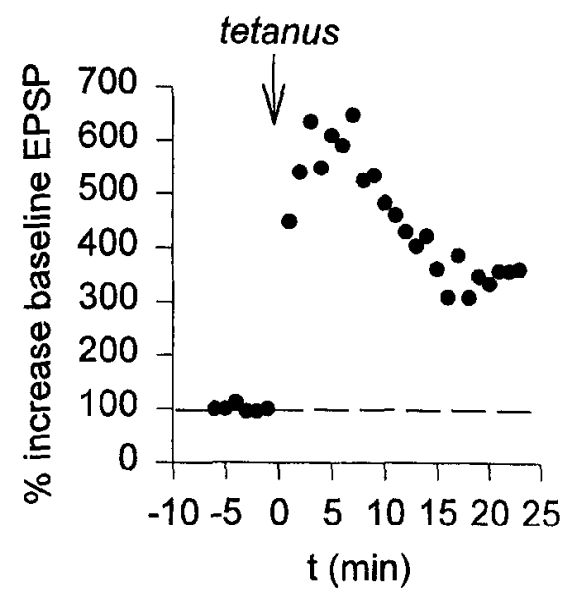

cell patch recording, which is advantageous for multiple pharmacological manipulations. Network excitability was evaluated by measuring the amplitude of the extracellularly recorded PS that results from activation of feedforward excitatory afferents by stimulation of the SR. The effect of Alv-evoked inhibition on the SR-elicited PS $\left(\mathrm{PS}_{\mathrm{SR}}\right)$ was measured by pairing Alv stimulation with SR stimulation ( $\mathrm{PS}_{\mathrm{Alv}, \mathrm{SR}}$ ) (see Materials and Methods, and Figs. 1, 4). The amplitude of the SR-evoked PS then was examined in the paired-pulse paradigm before and after tetanus of the Alv pathway (Fig. $4 A$ ). After the tetanus ( $>20 \mathrm{~min}$ ), a significant reduction of the $\mathrm{PS}_{\mathrm{Alv}, \mathrm{SR}} / \mathrm{PS}_{\mathrm{SR}}$ ratio of $15 \pm 2 \% \mathrm{SE}(\mathrm{N}=32 ; p<$ 0.005 , Wilcoxon signed-ranks test) in the absence of changes in the $\mathrm{PS}_{\mathrm{SR}}$ or the $\mathrm{PS}_{\mathrm{Alv}}$ was observed (Fig. $4 B, C$ ).

As with the intracellular recordings, we also examined the effects of the previously described pathway transection on inhibition in this paradigm. In all three transected slices tested, tetanic stimulation of the Alv caused a reduction of the $\mathrm{PS}_{\mathrm{Alv}, \mathrm{SR}} / \mathrm{PS}_{\mathrm{SR}}$ ratio $(20 \pm 6 \%)$, comparable to the reduction of the ratio observed in the nontransected slices.

The $\mathrm{PS}_{\mathrm{Alv}, \mathrm{SR}} / \mathrm{PS}_{\mathrm{SR}}$ ratio also was used to measure the sensitivity of Alv-evoked inhibitory LTP to the NMDA antagonists APV (Collingridge et al., 1983, Davis et al., 1992), PCP (Lodge et al., 1983) and NAAG (Mori-Okamoto et al., 1987; Puttfarcken and Coyle, 1989; Sekiguchi et al., 1989; Puttfarcken et al., 1993). The latter is an endogenous, acetylated, di-amino acid that is found in many CNS regions including the hippocampus together with its catabolic enzyme, $N$-acetyl-alphalinked-acidic-dipeptidase (NAALADase) (Blakely and Coyle, 1988; Stauch-Slasher et al., 1992). Both APV (Harris et al., 1984) and PCP (Stringer et al., 1983) have been shown to block L'I'P of excitatory Schaffer collateral input onto CA1 pyramidal cells, the former, in a dose-dependent manner. 
A.

1.

2.

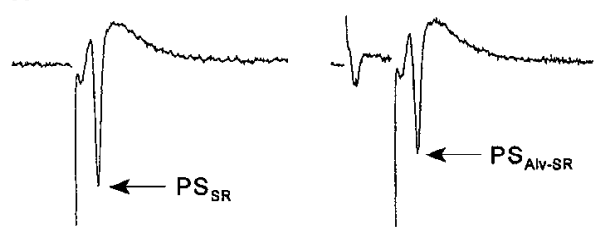

B.

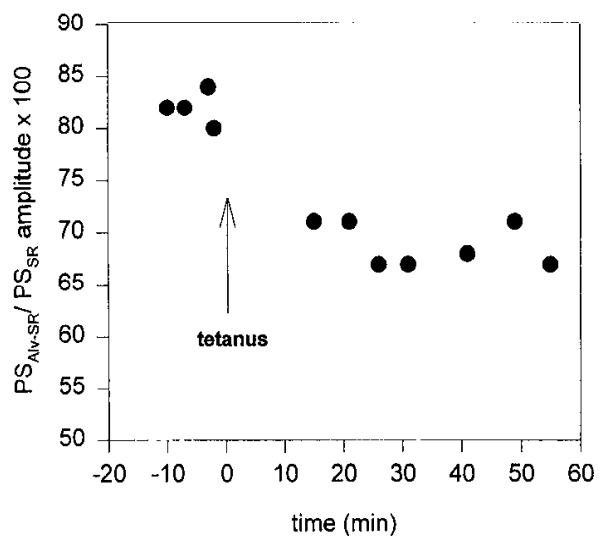

c.

1. control

2. post-tetanus ( $15 \mathrm{~min})$

3. post-tetanus $(40 \mathrm{~min})$

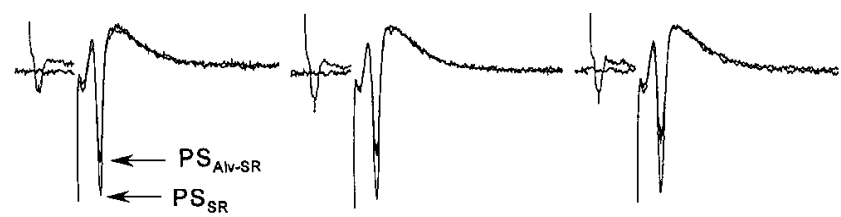

Figure 4. Tetanic stimulation of the alveus induces an LTP of the alvear-induced inhibition of the SR-evoked PS. $A$, Extracellular recordings of CA1 SP field potentials (PS) in response to SR stimulation $(1,2)$. Although the SR stimulation is identical in both cases, in the latter (2), a paired $A l v-S R$ stimulation was used with a resulting reduction of the PS amplitude. $B, \mathrm{~A}$ graph of the change in Alv-evoked inhibition, indicated by the $P S_{A l v, S R} P S_{S R}$ ratio with respect to the time of tetanus application, is illustrated. $C$, Superimposed traces of the unpaired $\mathrm{PS}_{\mathrm{SR}}$ and $\mathrm{PS}_{\mathrm{Alv}, \mathrm{SR}}$ are shown. Note the reduction in amplitude of the paired PS after the tetanus in the absence of change in either the unpaired $\mathrm{PS}_{\mathrm{SR}}$ or the alvear-evoked field potential (compare $l$ with 2 and 3 ).

In agreement with observations at the single neuron level, exposure to APV $(50 \mu \mathrm{M})$ during tetanic stimulation prevented LTP induction of $>10 \%$ in seven of eight slices tested as measured 20 min after tetanus by the $\mathrm{PS}_{\mathrm{Alv}, \mathrm{SK}} / \mathrm{PS}_{\mathrm{SR}}$ ratio $(0.85 \pm 0.03$ before tetanus; $0.87 \pm 0.03$, after), a significant difference from control conditions ( $p<0.05, \chi^{2}$ test). In addition, LTP also was prevented by the application of either PCP $(100 \mu \mathrm{M} ; n=6 ; p<$ $0.01, \chi^{2}$ test) or NAAG (100 $\mu \mathrm{m} ; n=3 ; p<0.05, \chi^{2}$ test) during the tetanus.

Furthermore, APV also caused a dose-dependent, reversible increase in the $\mathrm{PS}_{\mathrm{Alv}, \mathrm{SR}} / \mathrm{PS}_{\mathrm{SR}}$ ratio before application of the tetanus, similar to the dose-dependent decrease in the evoked IPSP amplitude seen in whole-cell recording experiments. The $\mathrm{PS}_{\mathrm{SR}}$ amplitude alone was unaffected by drug application. At a concentration of $25 \mu \mathrm{M} \mathrm{APV}$, the $\mathrm{PS}_{\mathrm{Alv}, \mathrm{SR}} / \mathrm{PS}_{\mathrm{SR}}$ ratio was increased reversibly by $17 \pm 8.5 \%(n=3)$. These data support the hypothesis that there is an NMDA-mediated component to Alvevoked inhibition.

Because antagonism of excitatory LTP has been reported to be dose-dependent (Harris et al., 1984), we compared the sensitivity of excitatory LTP of the Schaffer collateral input onto CA1 pyramidal cells with that of the LTP of Alv-evoked inhibition to NMDA receptor antagonism. The percent of LTP elicited under control conditions $(100 \%)$ is plotted against the concentrations of $\mathrm{APV}$, ranging from 0.3 to $50 \mu \mathrm{M}$ (Fig. $5 \mathrm{~A}$ ). Data points from each experimental paradigm were fit with a sigmoid equation (see Materials and Methods) using a least-squares analysis, and then the half-maximal responses were determined. LTP of the Alvevoked inhibition was found to be an order of magnitude more sensitive to NMDA receptor blockade than that of the SR-evoked excitatory LTP. The concentration of APV at which the LTP was reduced by $50 \%\left(\mathrm{IC}_{50}\right)$ was found to be $0.57 \pm 1.1 \mu \mathrm{M}$ for the inhibitory LTP, compared with $5.7 \pm 1.1 \mu \mathrm{M}$ for the excitatory LTP. Furthermore, in agreement with previous studics (Harris ct al., 1984) concentrations of APV $<3 \mu \mathrm{m}$ had little effect on the development of LTP in the excitatory pathway. In contrast, the LTP of the Alv-evoked inhibition was reduced by $\sim 80 \%$ at the concentration of APV of $1.5 \mu \mathrm{M}$. The endogenous NMDA antagonist NAAG $(50 \mu \mathrm{M})$ also selectively reduced LTP of the Alvevoked inhibition, while leaving excitatory LTP from SR stimulation unaffected (Fig. 5B).

In addition, we tested for differential sensitivity of the inhibitory versus excitatory LTP in transected slices. In agreement with data obtained from control slices, we found the same differential sensitivity for APV administered during tetanus. In this condition, all three slices tested (APV, $12.5 \mu \mathrm{M}$ ) showed no LTP of the Alvevoked inhibition, but SR-evoked excitatory LTP was expressed in every case.

The implications of a selective antagonism of LTP of recurrent inhibitory circuits (the likely source of alvear-evoked inhibition) on processing characteristics of CA1 neuronal networks then were examined with computer simulation based on simulations published previously (Traub et al., 1992; Barkai and Hasselmo, 1994; Hasselmo and Barkai, 1995) (for detailed description of simulation, see Materials and Methods). The effect of LTP at excitatory synapses in the network was modeled by strengthening of synaptic interactions between modeled neurons. As shown in Figure 6, we evaluated the ability of this network to store two different patterns of afferent input, each of which activated 40 neurons and overlapped with the other pattern by 8 neurons. (See representations of complete pattern 1 and pattern 2 in Figure 6A.)

Figure $6 A$ shows the response of the network before any learning (i.e., before strengthening of synapses in the network). The network responds with spiking activity attributable to direct afferent input to a subset of 40 neurons, considered a presentation of complete input patterns, and attributable to direct afferent input to 24 neurons, considered a presentation of degraded input patterns.

During a learning phase, LTP of excitatory synapses was applied at synapses experiencing both pre- and postsynaptic activity. During a separate recall phase, the network was capable of recalling specific patterns of action potential generation in modeled neurons. For example, the network was presented with degraded versions of the input patterns, which induced spiking directly in only 24 of the 40 original neurons activated by the full input. After the learning phase, the spread of activity across strengthened synapses then caused action potential generation in neurons not receiving afferent input from the degraded pattern but that were activated previously by the complete pattern.

The capability to recall missing elements of the stored pattern also enhanced the possibility that activity elicited by one pattern 
A

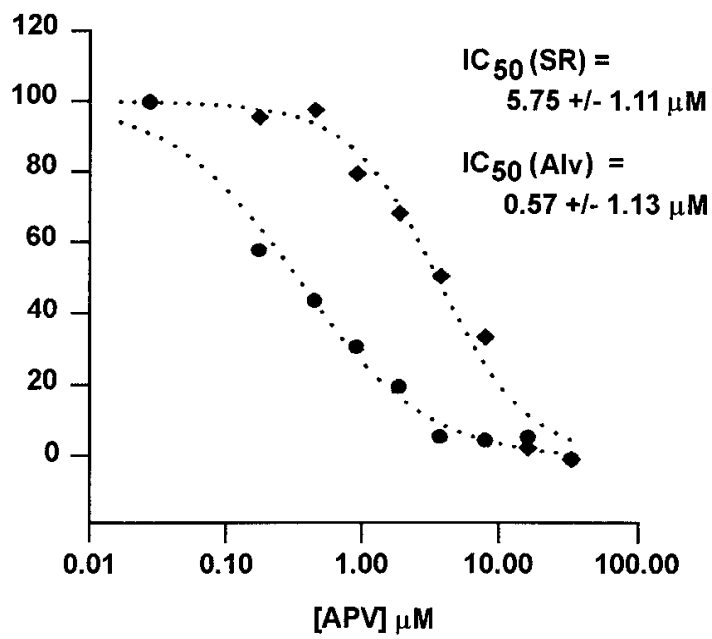

B

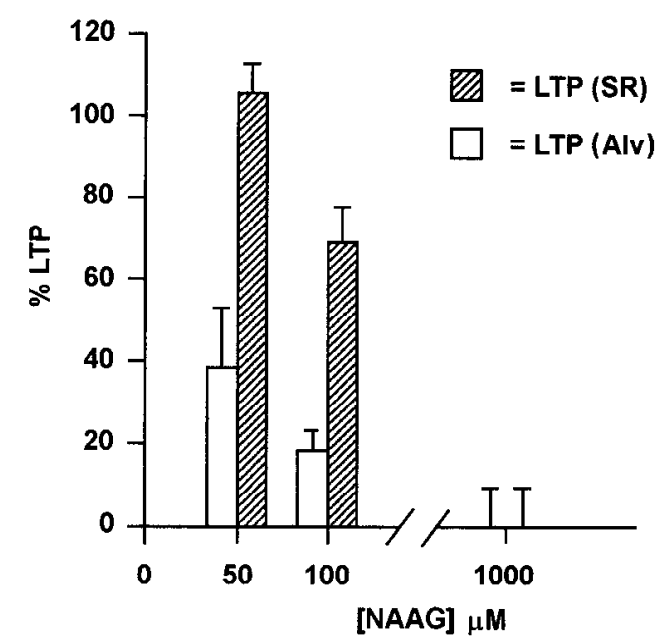

Figure 5. LTP of local circuit inhibition shows differential sensitivity to NMDA receptor antagonists compared with excitatory LTP. $A$, A dose-response relationship for the percent maximal LTP versus APV concentration (range 0.3-50 $\mu \mathrm{M}$ ). The two data points at $0.05 \mu \mathrm{M}$ (indicated by the overlapping solid circle and solid diamond) reflect the absence of APV and are used to facilitate curve fitting on the logarithmic scale. Each point represents the average of at least four experiments. LTP of recurrent inhibition (solid circle) shows a greater sensitivity to blockade by APV than excitatory LTP (solid diamond). $B$, A histogram illustrates the percent LTP versus the concentration of the endogenous NMDA receptor antagonist NAAG. The selective antagonism by NAAG of LTP evoked by Alv stimulation relative to that evoked by SR stimulation is similar to that of APV.

would spread into neurons activated by the other pattern, thus reducing or preventing the ability to differentiate between the patterns (see Figure $6 B$, lower trace). Strengthening of excitatory synapses from pyramidal cells to inhibitory interneurons prevented this problem. During recall, the network was tested both with and without the strengthening of excitatory input onto inhibitory interneurons. With strengthening of this recurrent inhibition, the network effectively recalled missing components without the spread of activity into other neurons of the second pattern (Figure $6 B$, top trace). Without strengthening of recurrent inhibition, during recall, activity spread into neurons representing both patterns, thereby preventing the ability to distinguish between overlapping stored patterns. Although temporal coding of information was not considered in this simulation, LTP of recurrent inhibition likely would play an important role in this aspect of processing as well.

\section{DISCUSSION}

In summary, the data presented here suggest that stimulation of the Alv in vitro evokes an inhibitory GABAergic input onto CA1 pyramidal neurons that is under the modulatory influence of NMDA-dependent transmission and is capable of NMDAdependent LTP. The Alv-induced inhibitory LTP was distinct pharmacologically from LTP of the Schaffer collateral-induced excitatory input to CA1 pyramidal neurons in that it had a greater sensitivity to the NMDA antagonists APV and NAAG. Specifically, the $\mathrm{IC}_{50}$ for inhibitory LTP was $0.57 \mu \mathrm{M}$ for APV, compared with $5.7 \mu \mathrm{M}$ for the excitatory LTP.

The observation that baseline inhibitory transmission can be reduced by NMDA receptor antagonists is consistent with the presence of NMDA receptors on inhibitory interneurons that can be activated from the resting membrane potential, as suggested by the $I / V$ relationship observed for 6-cyano-7-nitroquinoxaline-2,3dione-resistant EPSPs in these cells (Sah et al., 1990; Lacaille, 1991). A reduction of inhibitory transmission by NMDA receptor blockade has been reported in the hippocampus (Hablitz and
Langmoen, 1986) and the amygdala (Rainnie et al., 1991). Similarly, a role for NMDA-mediated transmission also has been reported for recurrent EPSPs in CA1 pyramidal cells based on the partial blockade by APV (Thompson and Radpour, 1991). In contrast, the NMDA-dependent current activated by Schaffer collateral input onto pyramidal neurons requires depolarization to remove an intrinsic $\mathrm{Mg}^{2+}$ blockade (Collingridge el al., 1988). The apparent difference in interneuron response could be explained if the interneurons have a more depolarized resting state than pyramidal neurons, thereby relieving some of the $\mathrm{Mg}^{2+}$ blockade. However, this does not appear to be true (Lacaille and Williams, 1990; Lacaille, 1991).

An alternative explanation is that hippocampal interneurons express NMDA receptors that differ from those expressed on CA1 pyramidal neurons. A differential distribution of receptor subtypes is not without precedent in the hippocampus (Bochet et al., 1994). The NMDA receptor also has several possible subunit conformations in which, in its most basic form, the NR1 subunit combines with one or more of the NR2A-D subunits to form a functional receptor (Moriyoshi et al., 1991; Monyer et al., 1992). These receptor subunits also show distinct regional and developmental distributions (Laurie and Seeburg, 1994; Monyer et al., 1994; Watanabe et al., 1994). For example, in the CA1 and CA3 regions of the hippocampus, NR2A and NR2B are prominent in pyramidal neurons, whereas the NR2C and NR2D subunits are prominent in subsets of interneurons (Monyer et al., 1994).

It is important to note in the context of this study that the NR2C and NR2D subunits, when combined with NR1 subunits, form functional receptor channels that have a lower sensitivity to $\mathrm{Mg}^{2+}$ blockade and a longer offset decay time (Moyner et al., 1994) than those formed in conjunction with NR2A or NR2B subunits. In addition, splice variants of the NR1 subunit have been reported to confer NMDA receptors with a differential sensitivity to antagonists (Nakanishi et al., 1992). These properties would predict that interneurons that contain either the NR2C or NR2D 


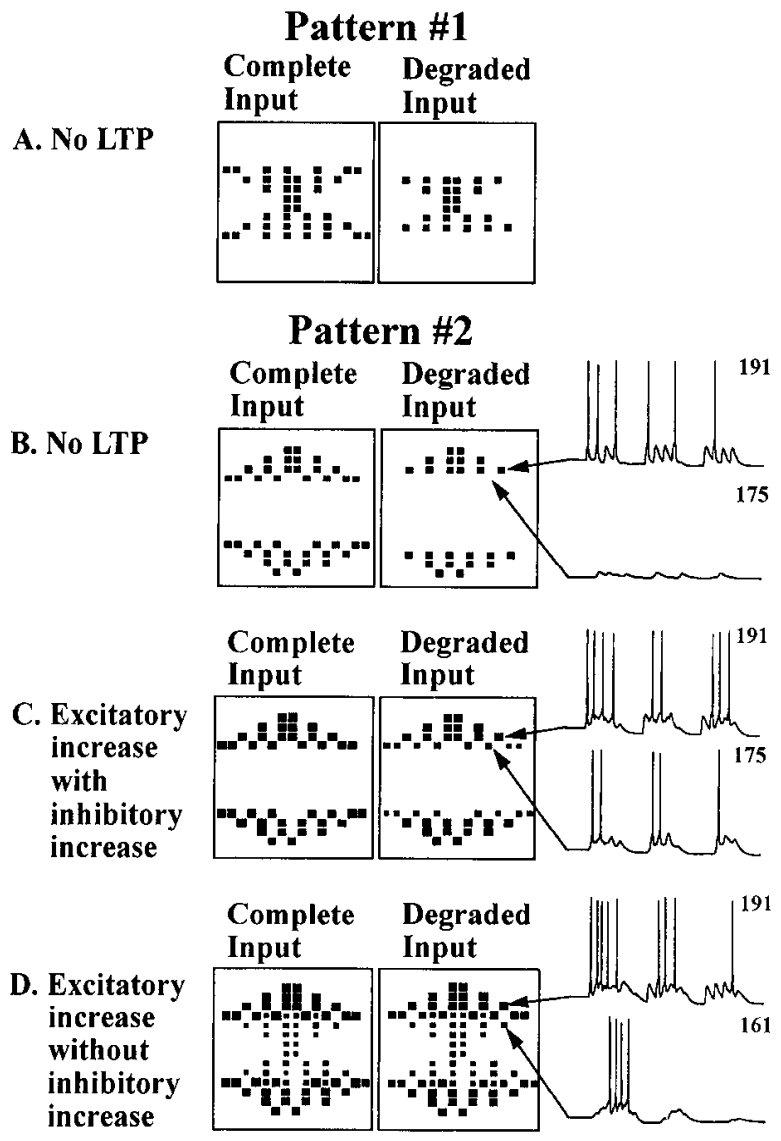

Figure 6. Activity in a network biophysical simulation showing the significance of LTP of recurrent inhibition for recall of stored input patterns. This figure illustrates activity during recall. Activity during learning is no shown. $A$, Spiking activity induced in a network of 240 pyramidal cells without any strengthening of excitatory intrinsic synapses. Each enclosed panel contains 240 neurons plotted in a $15 \times 16$ matrix. The size of the black squares represents the number of action potentials generated by each pyramidal cell during a $500 \mathrm{msec}$ period of recall. (To the right of pattern 2, traces illustrate the membrane potential of neurons 191 and 175. The solid square for 191 represents the six spikes generated by that neuron, which receives direct afferent input. The absence of a solid square for 175 represents the absence of spiking activity attributable to the absence of strong afferent input to this neuron). For each pattern, the left panel shows the response to the complete input version of the pattern (with 40 neurons active), and the right square shows the response to a degraded input version of the pattern (with 24 neurons activated by afferent input). $B$, The spiking activity in the network after learning strengthens the excitatory connections between active neurons (excitatory LTP). The network has been trained on both pattern 1 and pattern 2, but recall is shown only for the complete and degraded version of pattern 2. Activity is shown during a $500 \mathrm{msec}$ recall period with and without the strengthening of synapses between pyramidal cells and inhibitory interneurons (inhibitory LTP). $C$, With both excitatory LTP and inhibitory LTP, the network responds to the complete pattern with no excess spread of activity and responds to the degraded input with activity spreading only into neurons, which were a component of the original learned pattern. For example, on the right, the membrane potential traces show neuron 191 responding to afferent input, whereas neuron 175 responds because of synaptic activity spreading from other neurons. $D$, With excitatory LTP in the absence of inhibitory LTP, the network responds to both the complete and degraded versions of pattern 2 with activity, which spreads to components of the other stored pattern, pattern 1. This is attributable to the spread of activity from neurons, which were components of both patterns. This additional spread can be prevented hy stronger recurrent inhibition. On the right, membrane potential traces show the response of neuron 191 and the excess spread of activity into neuron 161. In this case, differentiation of the two patterns is prevented, because input of either pattern recalls elements of both patterns. subunit would be capable of detecting and responding to low levels of synchronicity in presynaptic terminals or to small postsynaptic depolarizations, and that if the appropriate NR1 splice variant also was present, these same interneurons would show a differential sensitivity to NMDA antagonists. The speculation that NMDA receptor subunit assembly in interneurons is different from that of projection neurons is consistent with the results reported in this paper.

The differential sensitivity to NMDA antagonists of inhibitory LTP compared with that of excitatory LTP may result from several nonmutually exclusive possibilities. First, our data suggest that APV can block an NMDA component of the EPSP onto the interneuron at concentrations comparable to those that block inhibitory LTP. Thus, inhibitory LTP may be reduced as a result of a reduced EPSP. The EPSP clicited by low-frequency Schaffer collateral stimulation has no such component under control conditions. Second, there may be different NMDA receptors with different affinities for NMDA antagonists on interneurons compared with those on pyramidal cells. Finally, the measurement of inhibitory LTP made in this study is indirect, i.c., the pathway is disynaptic, because LTP in the interneuron is evaluated by an increase in inhibition recorded in a projection neuron. A potential consequence of this disynaptic pathway is that small decreases in excitatory transmission may have large effects on the number of action potentials generated in the interneuron and, thus, result in a large decrease in inhibition. This may contribute to the differential sensitivity. However, it is likely that this contribution is small, at least with respect to the generation of LTP, because the slope of the APV concentration-response curve for inhibitory LTP is less than that of excitatory LTP. The reverse would be expected if the contribution were largc.

The functional change elicited by a selective antagonism of NMDA receptor activation on interneurons in the cortex might show regional variability, dependent on the degree of NMDA modulation of the local circuit inhibition and the network's dependence on that inhibition. The latter shows considerable regional variability as indicated by the limbic system's highly sensitive epileptogenic response $10 \mathrm{GABA}_{\mathrm{A}}$ antagonists (Traub et al., 1993) compared with other regions (Gruenthal et al., 1986). Although systemic exposure to NMDA antagonists does not result in sufficient disinhibition to elicit epileptiform activity (Javitt and Zukin, 1991; Krystal et al., 1994), Olney et al. (1991) have suggested that it is sufficient in at least the retrosplenial and posterior cingulate region of the limbic cortex to evoke excitotoxicity culminating in cell death.

The focus of this study is on the disynaptic recurrent inhibitory circuit. However, the possibility that along with the activation of recurrent inhibition, some feedforward inhibition was also activated with our protocol cannot be excluded completely, as is possible with the use of paired recordings (Miles and Wong, 1987; Miles, 1990). Using a paired-recording paradigm, an unambiguous activation of the recurrent circuit was obtained in the guinea pig CA3 region (Miles and Wong, 1987). It should be noted, however, that in examining this circuit for LTP, extracellular tetanic stimuli were used that tetanized both feedforward and feedback circuits. This resulted in a long-term reduction of the disynaptic recurrent inhibitory circuit. Tetanic activation of the alveus in adult Wistar rats (Haas and Rose, 1982) or guinea pig (Abraham et al., 1987) has been reported to have no effect or to evoke only a transient ( $<5 \mathrm{~min}$ ) increase in alveus-evoked IPSPs. Using juvenile Long-Evans hooded rats, we have attempted to restrict the tetanic activation of the alveus to $\mathrm{CA} 1$ pyramidal 
axons by prior lesion of the commisural feedforward axons together with an acute lesion that spared only the alveus with a resulting LTP of the recurrent inhibitory circuit.

Accordingly, the focus of the computer simulation was on the functional implications of selective disruption of the recurrent inhibitory circuit, and the role of feedforward inhibition was not included. This simplification was needed for the simulation, because feedforward inhibitory activation may well be independent of the input to the projection neurons, in contrast to the dependence of feedback activation. Also, it is less clear if the blockade of the NMDA-dependent LTP of feedforward inhibition will cause a similar dysfunction, because at least in some cases, it appears to be accompanied by a decrease in GABAergic receptor efficacy (Stelzer et al., 1994).

The simulations indicate that blockade of recurrent inhibitory LTP can disrupt normal CA1 neuronal processing by causing an abnormal increase in excitatory synaptic associations between pyramidal cells in an autoassociation network. The result can be a loss of distinctively patterned firing output in response to distinctively patterned input. This kind of associational interaction between projection neurons (Johnston and $\mathrm{Wu}, 1995$ ) is likely to occur to a limited extent in CAl (Thomson and Radpour, 1991) and to a greater extent in CA3 (Miles and Wong, 1986). The present study did not include the $\mathrm{CA} 3$ region because of the difficulty in restricting feedforward inhibition in this area.

The simulation did not include the NMDA modulation of the acute recurrent IPSP that is suggested by the IPSP reduction of $30 \%$ elicited by APV. The functional implications for this acute modulation of pattern differentiation are similar to those of selective blockade of inhibitory LTP. Because only a modulatory influence is blocked by NMDA antagonists, the effect on excitability is subtle, unlike a full blockade of $\mathrm{GABA}_{\mathrm{A}}$ inhibition, which elicits epileptiform activity (Schwartzkroin and Prince, 1977).

Finally, the selective sensitivity of local circuit inhibitory LTP to NAAG has potentially important clinical ramifications. Recent postmortem studies of brains of schizophrenic patients indicate localized increases in NAAG levels, associated with decreases in its catabolic enzyme NAALADase that are especially prominent in the hippocampus (Tsai et al., in press). The findings from the present study indicate that NAAG, by antagonism of the NMDA receptor, may induce a selective reduction of the recurrent EPSP exciting interneurons and interneuronal LTP. Together with the postmortem data, the possibility may be raised that this action of NAAG has a pathophysiological role in schizophrenia.

\section{REFERENCES}

Abraham WC, Gustafsson B, Wigström H (1987) Long-term potentiation involves enhanced synaptic excitation relative to synaptic inhibition in guinea-pig hippocampus. J Physiol (Lond) 394:367-380.

Alger BE, Nicoll RA (1982) Feed-forward dendritic inhibition in rat hippocampal pyramidal cells studied in vitro. $\mathbf{J}$ Physiol (Lond) 328:105-123.

Amaral DG, Witter M (1989) The three dimensional organization of the rat hippocampal formation: a review of anatomical data. Neuroscience 31:571-591.

Andersen P, Eccles JC, Løyning Y (1963) Recurrent inhibition in the hippocampus with identification of the inhibitory cell and its synapses. Nature 198:540-542.

Anderson P, Sundberg SH, Sveen O, Wigström H (1977) Specific longlasting potentiation of synaptic transmission in hippocampal slices. Nature 266:736-737.

Barkai E, Hasselmo ME (1994) Modulation of the input/output function of rat piriform cortex pyramidal cells. J Neurophysiol 72:644-658.
Barkai E, Bergman RE, Horwitz G, Hasselmo ME (1994) Modulation of associative memory function in a biophysical simulation of rat piriform cortex. J Neurophysiol 72:659-677.

Blakely RD, Coyle JT (1988) The neurobiology of N-acetylaspartylglutamate. Int Rev Neurobiol 30:39-100.

Blanton MG, Lo Turco JJ, Kriegstein AR (1989) Whole cell recording from neurons in slices of reptilian and mammalian cerebral cortex. J Neurosci Methods 30:203-210.

Bliss TVP, Collingridge GL (1993) A synaptic model of memory: longterm potentiation in the hippocampus. Nature 361, 31-39.

Bliss TVP, Lømo T (1973) Long lasting potentiation of synaptic transmission in the dentate area of the anaesthetized rabbit following stim ulation of the perforant path. J Physiol (Lond) 232:331-356.

Bochet P, Audinat E, Lambolez B, Crépel F, Rossier J, Iino M, Tsuzuki K, Ozawa $S$ (1994) Subunit composition at the singlc- ccll level explains functional properties of a glutamate-gated channel. Ncuron 12:383-388.

Bourne GW, Théorêt Y, Esplin B, Capek R (1983) Effect of phencyclidine on inhibition in the hippocampal slice. Naunyn-Schmiedcbergs Arch Pharmacol 323:168-172.

Bower JM, Beeman D (1995) The book of genesis: exploring realistic neural models with the general neural simulation system. New York: Telos/Springer-Verlag.

Buhl EIl, Halasy K. Somogyi P (1994) Diverse sources of hippocampal unitary inhibitory postsynaptic potentials and the number of synaptic release sitcs. Nature 368:823-828.

Buzsáki G, Eidelberg E (1982) Direct afferent excitation and long-term potentiation of hippocampal interncurons. J Neurophysiol 48:597-607.

Buzsáki G, Horváth Z, Urioste R, Hetke J, Wise K (1992) High-frequency network oscillation in the hippocampus. Science 256:1025-1027.

Collingridge GL, Keel SJ, McLennan H (1983) Excitatory amino acids in synaptic transmission in the Chaffer collateral-commissural pathway of the rat hippocampus. J Physiol (Lond) 334:33-46.

Collingridge GL, Herron CE, Lester RAJ (1988) Synaptic activation of $N$-methyl-D-aspartate receptors in the Chatfer collateral-commissural pathway of rat hippocampus. J Physiol (Lond) 399:283-300.

Curtis DR, Felix D, McLellan H (1970) GABA and hippocampal inhibition. Br J Pharmacol 40:881-883.

Davis S, Butcher SP, Morris RGM (1992) The NMDA receptor antagonist D-"-amino-\%-phosphopentanoate (D-APV) impairs spatial learning and LTP in vivo at intracerebral concentrations comparable to those that block LTP in vitro. J Neurosci 12:21-34.

Dingledine R, Langmoen IA (1980) Conductance changes and inhibitory actions of hippocampal recurrent i.p.s.p.s. Brain Res 185:277-287.

Frotscher M, Zimmer J (1983) Commissural fibers terminate on nonpyramidal neurons in the guinea pig hippocampus-a combined Golgi/EM degeneration study. Brain Res 265:289-293.

Gruenthal M, Armstrong DR, Ault B, Nadler JC (1986) Comparison of seizures and brain lesions produced by intracerebroventricular kainic acid and bicuculline methiodide. Exp Neurol 93:621-630.

Haas HL, Rose G (1982) Long-term potentiation of excitatory synaptic transmission in the rat hippocampus: the role of inhibitory processes. J Physiol (Lond) 329:541-552.

Hablitz JJ, Langmoen IA (1986) $N$-methyl-D-aspartatc receptor antagonists reduce synaptic excitation in the hippocampus. J Neurosci 6:102-106.

Harris W, Ganong AH, Cotman CW (1984) Long-term potentiation in the hippocampus involves activation of $N$-methyl-D-aspartate receptors. Brain Res 323:132-137.

Hasselmo ME, Barkai E (1996) Cholincrgic modulation of activitydependent synaptic plasticity in the piriform cortex and associative memory function in a network biophysical simulation. J Neurosci, in press.

Hasselmo ME, Bower JM (1993) Acetylcholine and memory. Trends Neurosci 16:218-222.

Herron CE, Lester RAJ, Coan EJ, Collingridge GL (1986) Frequencydependent involvement of NMDA receptors in the hippocampus: a novel synaptic mechanism. Nature 322:265 268.

Hestrin S, Nicoll RA, Perkel DJ, Sah P (1990) Analysis of excitatory synaptic action in pyramidal cells using whole cell recordings fro rat hippocampal slices. J Physiol (Lond) 422:203-225.

Javitt DC, Zukin SR (1991) Recent advances in the phencyclidine model of schizophrenia. Am J Psychiatry 148:1301-1308.

Johnston D, Wu, SM-S (1995) Foundations of cellular neurophysiology. Cambridge, MA: MIT 
Korn H, Oda Y, Faber DS (1992) Long-term potentiation of inhibitory circuits and synapses in the central nervous system. Proc Natl Acad Sci USA 89:440-443.

Krystal JH, Karper LP, Seibyl JP, Freeman GK, Delaney R, Brenner JD, Heninger GR, Bowers MB Jr, Charney DS (1994) Subanesthetic effects of the noncompetitive NMDA antagonist, ketamine, in humans. Arch Gen Psychiatry 51:199-214.

Lacaille JC (1991) Postsynaptic potentials mediated by excitatory and inhibitory amino acids in interneurons of stratum pyramidale of the CA1 region of rat hippocampal slices in vitro. $J$ Neurophysiol 66:1441-1454.

Lacaille JC, Williams S (1990) Membrane properties of interneurons in stratum oriens-alveus of the CA1 region of rat hippocampus in vitro. Neuroscience 36:349 359

Laurie DJ, Seeburg H (1994) Regional and developmental heterogeneity in slicing of the rat brain NMDAR1 mRNA. J Neurosci 14:3180-3194.

Léránth CS, Frotscher M (1983) Conmissural afferents to the rat hippocampus terminate on vasoactive intestinal polypeptide-like immunoreactive non-pyramidal ncurons: an EM immunocytochemical degeneration study. Brain Res 276:357-361.

Li XG, Somogyi P, Ylinen A, Buzsáki G (1994) The hippocampal CA3 network: an in vivo intracellular labeling study. J Comp Neurol 339:181-208

Lodge D, Ands NA, Berry SC, Burton NR (1983) Arylcyclohexylamines selectively reduce excitation of mammalian neurones by aspartate-like amino acids. In: Phencyclidine and related arylcyclohexylamines (Kamenka JM, Domino EF, Geneste P, eds), pp 595-616. Ann Arbor, MI:NPP Books.

Malenka RC, Nicoll RA (1993) NMDA-receptor-dependent synaptic plasticity: multiple forms and mechanisms. Trends Neurosci 16:521-527.

Malinow R, Miller JP (1986) Postsynaptic hyperpolarization during conditioning reversibly blocks induction of long-term potentiation. Nature 320:529-530.

Miles R (1990) Synaptic excitation if inhibitory cells by single CA3 hippocampal pyramidal cells of the Guinea-pig in vitro. $\mathbf{J}$ Physiol (Lond) 428:61-77.

Miles R, Wong RKS (1986) Excitatory synaptic interactions between CA3 neurones in the guinea-pig hippocampus. J Physiol (Lond) 373:397-418.

Miles R, Wong RKS (1987a) Inhibitory control of local excitatory circuits in the guinea-pig hippocampus. J Physiol (Lond) 388:611-629.

Miles R, Wong RKS (1987b) Latent synaptic pathways revealed after tetanic stimulation in the hippocampus. Nature 329:724-726.

Monyer H, Sprengel R, Schoepfer R, Herb A, Higuchi M, Lomeli H, Burnashev N, Sakmann B, Seeburg PH (1992) Heterumeric NMDA receptors: molecular and functional distinction of subtypes. Science 256:1217-1221.

Monyer H, Burnashev N, Laurie DJ, Sakmann B, Seeburg PH (1994) Developmental and regional expression in the rat brain and functional properties of four NMDA receptors. Neuron 12:529-540.

Mori-Okamoto J, Okamoto K, Sekiguchi M (1987) Electrophysiological and pharmacological actions of $N$-acetylaspartylglutamate intracellularly studied in cultured chick cerebellar neurons. Brain Res 401:60-67.

Moriyoshi K, Masu M, Ishii T, Shigemoto R, Mizuno N, Nakanishi S (1991) Molecular cloning and characterization of the rat NMDA receptor. Nature 354:31 37

Nakanishi N, Axel R, Schneider NA (1992) Alternative splicing generates functionally distinct $N$-methyl-D-aspartate receptors. Proc Nat Acad Sci USA 89:8552-8556.

Olney JW, Labruyere J, Wang G, Wozniak DF, Price MT, Sesma MA (1991) NMDA antagonist neurotoxicity: mechanism and prevention. Science 254:1515-1518.
Puttfarcken PS, Coyle JT (1989) $N$-acetylaspartylglutamate (NAAG): A possible modulator of $\left[{ }^{3} \mathrm{H}\right]$ MK 801 binding in rat hippocampal membranes. Soc Neurosci Abstr 15:942.

Puttfarcken PS, Handen JS, Montgomery DT, Coyle JT, Werling LL (1993) $\mathrm{N}$-acetyl-aspartylglutamate modulation of $\mathrm{N}$-methyl-D-aspartatestimulated $\left[{ }^{3} \mathrm{H}\right]$ norepinephrine release from rat hippocampal slices. J Pharmacol Exp Ther 266:796-803.

Radpour S, Thomson AM (1991) Co-activation of local circuit NMDA receptor mediated EPSPs induces lasting enhancement of minimal Chaffer collateral EPSPs in slices of rat hippocampus. Eur J Neurosci 3:602-613.

Rainnie DG, Asprodini EK, Shinnick-Gallagher P (1991) Excitatory transmission in the basolateral amygdala. J Neurophysiol 66:986-998.

Sah P, Hestrin S, Nicoll RA (1990) Properties of excitatory postsynaptic currents recorded in vitro from rat hippocampal interneurones. J Physiol (Lond) 430, 605-616.

Schwartzkroin PA, Prince DA (1977) Penicillin-induced epileptiform activity in the hippocampal in vitro preparation. Ann Neurol 1:463-469.

Sekiguchi M, Okamoto K, Sakai Y (1989) Low-concentration $N$-acetylaspartylglutamate suppresses the climbing fiber response of Purkinje cells in guinea pig cerebellar slices and the response to excitatory amino acids of Xenopus laevis oocytes injected with cercbellar mRNA. Brain Res 482, 87-96.

Spencer WA, Kandel ER (1961) Hippocampal neuron responses to selective activation of recurrent collaterals of hippocampofugal axons. Exp Ncurol 4:149-161.

Stauch-Slusher BS, Tsai G, Voo G, Coyle JT (1992) Immunocytochemical localization of the $N$-acetyl-aspartyl-glutamate (NAAG) hydrolyzing enzyme $\mathrm{N}$-acetylated alpha-linked acidic dipeptidase (NAALADase). J Comp Neurol 315:217-229.

Stelzer A (1992) GABA $_{\mathrm{A}}$ receptors control the excitability of neuronal populations. Int Rev Neurobiol 33:195-287.

Stelzer A, Simon G, Kovacs G, Rai R (1994) Synaptic disinhibition during maintenance of long-term potentiation in the CA 1 hippocampal subfield. Proc Natl Acad Sci USA 91:3058-3062.

Stringer JL, Greenfield LJ, Hackett JT, Guyenet PG (1983) Blockade of long-term potentiation by phencyclidine and $\sigma$ opiates in the hippocampus in vivo and in vitro. Brain Res 280:127-138.

Thomson AM, Radpour S (1991) Excitatory connections between CA 1 pyramidal cells revealed by spike triggered averaging in slices of rat hippocampus are partially NMD $\Lambda$ receptor mediated. Eur J Ncurosci 3:587-601.

Traub R, Miles R, Buzsáki G (1992) Computer simulation of carbacholdriven rhythmic population oscillations in the CA3 region of the in vitro rat hippocampus. J Physiol (Lond) 451:653-672.

Traub R, Miles R, Jeffereys JGR (1993) Synaptic and intrinsic conductances shape picrotoxin-induced synchronized after discharges in the guinea-pig hippocampal slice. J Physiol (Lond) 461:525-547.

Tsai G, Passani L $\Lambda$, Slusher BS, Carter R, Kleinman JE, Coyle JT (1996) Changes of excitatory neurotransmitter metabolism in schizophrenic brains. Arch Gen Psychiatry, in press.

Watanabe $M$, Mishina $M$, Inoue $Y$ (1944) Distinct spatiotemporal expressions of five NMDA receptor channel subunit mRNAs in the cerebellum. J Comp Neurol 343:513-519.

Whittington MA, Traub RD, Jeffereys JGR (1995) Synchronized oscillations in interneuron networks driven by metabotropic glutamate receptor activation. Nature 373:612-615.

Wilson MA, Bower JM (1992) Cortical oscillations and temporal interactions in a computer simulation of piriform cortex. J Neurophysiol 67:981-995. 